\title{
Analysis of direct costs of decompressive craniectomy in victims of traumatic brain injury
}

\section{Análise dos custos diretos da craniectomia descompressiva em vítimas de traumatismo cranioencefálico}

\author{
Guilherme Lellis Badke1, João Luiz Vitorino Araujo, 2,3, Flávio Key Miura', Vinicius Monteiro de Paula \\ Guirado', Nelson Saade', Aline Lariessy Campos Paiva', Tiago Marques Avelar', Charles Alfred Grander \\ Pedrozo', José Carlos Esteves Veiga'
}

\begin{abstract}
Background: Decompressive craniectomy is a procedure required in some cases of traumatic brain injury (TBI). This manuscript evaluates the direct costs and outcomes of decompressive craniectomy for TBI in a developing country and describes the epidemiological profile. Methods: A retrospective study was performed using a five-year neurosurgical database, taking a sample of patients with TBI who underwent decompressive craniectomy. Several variables were considered and a formula was developed for calculating the total cost. Results: Most patients had multiple brain lesions and the majority (69.0\%) developed an infectious complication. The general mortality index was 68.8\%. The total cost was $\mathrm{R} \$ 2,116,960.22$ (US\$ 661,550.06) and the mean patient cost was $\mathrm{R} \$ 66,155.00$ (US\$20,673.44). Conclusions: Decompressive craniectomy for TBI is an expensive procedure that is also associated with high morbidity and mortality. This was the first study performed in a developing country that aimed to evaluate the direct costs. Prevention measures should be a priority.
\end{abstract}

Keywords: decompressive craniectomy; brain injuries; cost and cost analysis; intracranial pressure.

\section{RESUMO}

Introdução: A craniectomia descompressiva (CD) é procedimento necessário em alguns casos de trauma cranioencefálico (TCE). Este manuscrito objetiva avaliar os custos diretos e desfechos da CD no TCE em um país em desenvolvimento e descrever o perfil epidemiológico. Métodos: Estudo retrospectivo foi realizado usando banco de dados neurocirúrgico de cinco anos, considerando amostra de pacientes com TCE que realizaram CD. Algumas variáveis foram analisadas e foi desenvolvida uma fórmula para cálculo do custo total. Resultados: A maioria dos pacientes teve múltiplas lesões intracranianas, sendo que $69.0 \%$ evoluíram com algum tipo de complicação infecciosa. A taxa de mortalidade foi de $68,8 \%$. O custo total foi $R \$ 2.116 .960,22$ (US\$ 653,216.00) e o custo médio por paciente foi R\$ $66.155,00$ (US\$ 20,415.00). Conclusões: CD no TCE é um procedimento caro e associado á alta morbidade e mortalidade. Este foi o primeiro estudo realizado em um país em desenvolvimento com o objetivo de avaliar os custos diretos. Medidas de prevenção devem ser priorizadas.

Palavras-chave: craniectomia descompressiva; lesões encefálicas; custos e análise de custo; pressão intracraniana.

\section{INTRODUCTION}

Decompressive craniectomy is a common neurosurgical procedure in which a skullcap portion of bone is removed and an opening is made in the underlying dura mater ${ }^{1}$, aiming to relieve raised intracranial pressure. Because of the skull rigidity, brain swelling or focal lesions lead to increased intracranial pressure and so decrease cerebral perfusion pressure, cerebral blood flow and oxygenation ${ }^{2}$. As well, with these brain hemodynamic changes, cerebral edema increases and could finally evolve into herniation and death ${ }^{3}$.

This procedure is used in several conditions in which this cascade occurs, such as in stroke and in traumatic brain injury (TBI) with cerebral edema ${ }^{4}$. Decompressive craniectomy is a method capable of disrupting this cycle and restoring brain

${ }^{1}$ Santa Casa de São Paulo, Faculdade de Ciências Médicas, Disciplina de Neurocirurgia, São Paulo SP, Brasil;

${ }^{2}$ Hospital Israelista Albert Einstein, São Paulo SP, Brasil;

${ }^{3}$ Instituto do Câncer Arnaldo Vieira de Carvalho, São Paulo SP, Brasil;

Correspondence:Aline Lariessy Campos Paiva; Disciplina de Neurocirurgia da Faculdade de Ciências Médicas da Santa Casa de São Paulo (FCMSCSP); Rua Dr. Cesário Motta Júnior, 112;01221-020 São Paulo SP, Brasil; E-mail: lariessy@hotmail.com

Conflict of interest: All authors certify that they have no affiliationswith or involvement in any organization or entity with any financial interest (such as honoraria; educational grants; participation in speakers' bureaus; membership, employment, consultancies, stock ownership, or other equity interest; and expert testimony or patent-licensing arrangements), or non-financial interest (such as personal or professional relationships, affiliations, knowledge or beliefs) in the subject matter or materials discussed in this manuscript.

Received 17 April 2017; Received in final form 07 December 2017; Accepted 19 December 2017. 
functionality ${ }^{1}$ when it is properly indicated and performed within a few hours of evaluation.

Despite several studies having described this topic, the indication for decompressive craniectomy remains under discussion, as well as the appropriate time within which this surgery could bring about a benefit. The effect of this procedure on long-term functional prognosis and costs is also a concern ${ }^{5}$. Decompressive craniectomy has been used for raised intracranial pressure from several etiologies, such as aneurysmal subarachnoid hemorrhage, encephalitis, acute demyelinated encephalomyelitis, cerebral venous thrombosis and parenchymal hemorrhagic stroke. However, the most important studies and evidences are greater for its use in TBI and stroke ${ }^{1}$.

Because TBI is a significant cause of morbidity and mortality globally, accurate research on this theme is very relevant for the public health system. However, most reported studies have described technical features, prognosis and life quality $^{6,7}$, whereas the direct costs and economic evaluation of TBI are variables that have been less studied but nonetheless are essential for resource allocation and improvement of patient management.

An example of the economic impact of this situation was demonstrated by 2012 data from the Brazilian public health system, which estimated that, in that year, about one million patients were admitted in hospitals because of external causes (TBI included) and the mean hospitalization cost was $\mathrm{R} \$ 1,079.60$ (US\$ 337.38). This represented more than one billion Brazilian Reais for the public health system's account ${ }^{8}$.

Severe TBI presents a poor outcome in most cases 9 Aggressive and expensive treatment for severe TBI is therefore a controversial topic because, besides being an optimal therapeutic, it has a high morbidity and mortality rate $^{5}$. Prevention is essential to decrease the number of trauma patients and should be encouraged as therapeutic approaches are very limited in improving outcomes in severe cases. Controlling traffic speed limits, alcohol ingestion and seatbelt use help to reduce traffic accidents that are a major cause of severe TBI.

This study aimed to evaluate the direct costs of decompressive craniectomy in patients with TBI in a developing country and to describe the epidemiological profile of these patients.

\section{METHODS}

An observational and retrospective study was performed using the Neurosurgical Department database of Santa Casa de São Paulo, Brazil in the period between February 2010 and February 2015.

All study procedures were in accordance with the ethical standards of the institutional and/or national research committee and with the 1964 Helsinki declaration and its later amendments or comparable ethical standards. The local institution's Human Ethics Research Committee had previously approved this project.

An extensive literature review using the Pubmed database was also performed, with the terms: decompressive craniectomy, brain trauma injury, costs. All patients with doubtful and conflicting information were excluded.

All the patients who had undergone decompressive craniectomy after TBI had cerebral hemisphere edema (with or without focal lesions, especially subdural hematoma) with a major midline shift (greater than $5 \mathrm{~mm}$ ). A standard decompressive hemicraniectomy was performed through a question mark or a T- (Becker) incision. A craniectomy, including the removal of the temporal tip, was performed, followed by the dural opening. A dura replacement was not used. In some cases, the pericranium was sutured to the dura and, in others, a rapid closure technique was performed.

Cost calculation of the entire procedure was determined through a detailed evaluation of surgical material, human labor, drugs, blood products, parenteral nutrition, imaging examinations, laboratory tests, days of hospitalization and deaths. The value was initially calculated in Brazilian Reais and later converted to US Dollars (this conversion was performed using the January 13, 2017 exchange rate in which US\$ 1 corresponds to R\$3.2).

After the data collection, statistical analysis was performed using a free $\mathrm{R}$ software program (3.3.0 version) and IBM SPSS 20 version software. The following parameters were used: mean, median, standard deviation, minimum and maximum for summarizing the quantitative variables. For categorical variables, absolute and relative frequencies (\%) were applied. Fisher's exact test was used to evaluate the association among categorical variables. For comparing two groups considering quantitative variables, the unpaired Mann-Whitney U-test was used and for comparing more than two groups, the non-parametric Kruskal-Wallis test was chosen.

Spearman's correlation coefficient was used to evaluate the linear correlation between two quantitative variables. The Kaplan-Meier survival index was used for estimating the hospitalization time until discharge. In addition, the log-rank test was performed for comparing time until discharge.

\section{RESULTS}

During this period, the neurosurgical department performed 5,223 surgeries, of which 1,030 were TBI and, when considering only the decompressive craniectomies for trauma, a total of 133 surgeries were performed (Table 1). A random selection of 32 patients with a TBI diagnosis, who underwent decompressive craniectomy, were selected.

The male gender predominated in this survey, totaling $84.4 \%$, whereas only five patients $(15.6 \%)$ were female. The average age was 44 years, the youngest patient was 15 yearsold and the oldest was 75 years of age (Table 2). 
Table 1. Description of all neurosurgical procedures performed during the period of February 2010 to February 2015 at Santa Casa de São Paulo, Brazil.

\begin{tabular}{|cccc}
\hline Year & $\begin{array}{c}\text { Number of } \\
\text { surgeries }\end{array}$ & $\begin{array}{c}\text { Traumatic brain } \\
\text { injury surgeries }\end{array}$ & $\begin{array}{c}\text { Decompressive } \\
\text { craniectomy } \\
\text { due to traumatic } \\
\text { brain injury }\end{array}$ \\
\hline 2010 & 687 & 107 & 30 \\
\hline 2011 & 866 & 164 & 14 \\
\hline 2012 & 980 & 209 & 20 \\
\hline 2013 & 987 & 196 & 25 \\
\hline 2014 & 847 & 182 & 15 \\
\hline 2015 & 856 & 172 & 29 \\
\hline Total & 5223 & 1030 & 133 \\
\hline
\end{tabular}

Table 2. General characteristics of the patients.

\begin{tabular}{|c|c|}
\hline Variable & Number of patients \\
\hline \multicolumn{2}{|l|}{ Gender } \\
\hline Male & $27(84.4 \%)$ \\
\hline Female & $5(15.6 \%)$ \\
\hline \multicolumn{2}{|l|}{ Age } \\
\hline $15-30$ years & $5(15.0 \%)$ \\
\hline $31-45$ years & $13(41.0 \%)$ \\
\hline$>45$ years & $14(44.0 \%)$ \\
\hline \multicolumn{2}{|c|}{ Admission Glasgow Coma Scale scores } \\
\hline Severe $(\leq 8)$ & $21(65.6 \%)$ \\
\hline Moderate (9-12) & $7(21.9 \%)$ \\
\hline Mild (13-15) & $4(12.5 \%)$ \\
\hline \multicolumn{2}{|l|}{ Time until the surgery } \\
\hline$<6 h$ & $9(28.0 \%)$ \\
\hline $6-12 h$ & $12(37.0 \%)$ \\
\hline $13-24 h$ & $5(16.0 \%)$ \\
\hline$>24 h$ & $6(19.0 \%)$ \\
\hline \multicolumn{2}{|l|}{ Operated side } \\
\hline Right & $11(34.4 \%)$ \\
\hline Left & $20(62.5 \%)$ \\
\hline Both & $1(3.1 \%)$ \\
\hline \multicolumn{2}{|c|}{ Discharge Glasgow Outcome Score (GOS) } \\
\hline Mortality $(\mathrm{GOS}=1)$ & $22(68.8 \%)$ \\
\hline Poor outcome (GOS = 2 and 3 ) & $5(15.6 \%)$ \\
\hline Good outcome (GOS = 4 and 5) & $5(15.6 \%)$ \\
\hline
\end{tabular}

Of the comorbidities, $22.0 \%$ of patients were alcoholics, $18.7 \%$ had hypertension and $6.2 \%$ had diabetes. No other associated pathologies were described.

Most of the patients had multiple brain lesions and the most frequent were acute subdural hematoma (68.7\%), diffuse brain edema (56.3\%) and contusion (50.0\%). Besides these, at a lower frequency, traumatic subarachnoid hemorrhage (18.7\%), epidural hematoma (9.4\%) and cranial gunshot wounds $(9.4 \%)$ were described. Considering the topography, the majority presented with a left hemisphere lesion (62.5\%).

Regarding infectious complications, 69.0\% developed some type of infection, such as pneumonia, meningitis, urinary tract infection and sepsis.

Most of the patients arrived at hospital in a severe general status. On admission, 21 of the 32 (65.6\%) patients presented with a Glasgow Coma Scale (GCS) $\leq$ 8; $21.9 \%$ with a GCS varying between 9 and 13; and only $12.5 \%$ had mild TBI. The mean time between arrival at the hospital and the surgical procedure was eight hours; however, with great variability (standard deviation (SD) of 39.2 hours and variation of $2-144$ hours). The mean hospitalization time was 40.3 days with a SD of 48.9 days and variation of 2-230 days.

The economic impact of decompressive craniectomy for TBI was measured by calculating the whole cost. A linear and positive correlation between days of hospitalization and the cost can be seen in Figure 1. Considering the other variables in relation to the cost, after a linear regression model analysis, none demonstrated a significant correlation.

Therefore, knowing what affects the cost, an equation was proposed considering the surgical procedure cost and days of hospitalization for calculating of the whole cost.

The expected cost formula in Brazilian Reais $(\mathrm{R} \$$ ) is below:

Expected cost $(\mathrm{R} \$)=3,858.921+1,334.78 \times$ Time of Hospitalization*

* Time of hospitalization in days; $\mathrm{R} \$ 3,858.921$ refers to the inherent procedure cost.

For example, a patient hospitalized for 60 days has an estimated cost of $\mathrm{R} \$ 92,435.35$ (US\$ 28,886.05) (Figure 2). This is a high value considering that the minimum Brazilian wage is US\$ 292.81 per month (this conversion was performed using the January 13, 2017 quotation in which US\$ 1 corresponded to $\mathrm{R} \$ 3.2$ ).

The variables correlating with a greater time of hospitalization were the severity of the trauma - patients with severe TBI had a positive correlation with increased costs (Figure 3) and infectious complications led to longer hospitalization times (Figure 4).

Comparing hospitalization days with the outcomes, it can be seen that survivors had a longer period of hospitalization (Figure 5) 


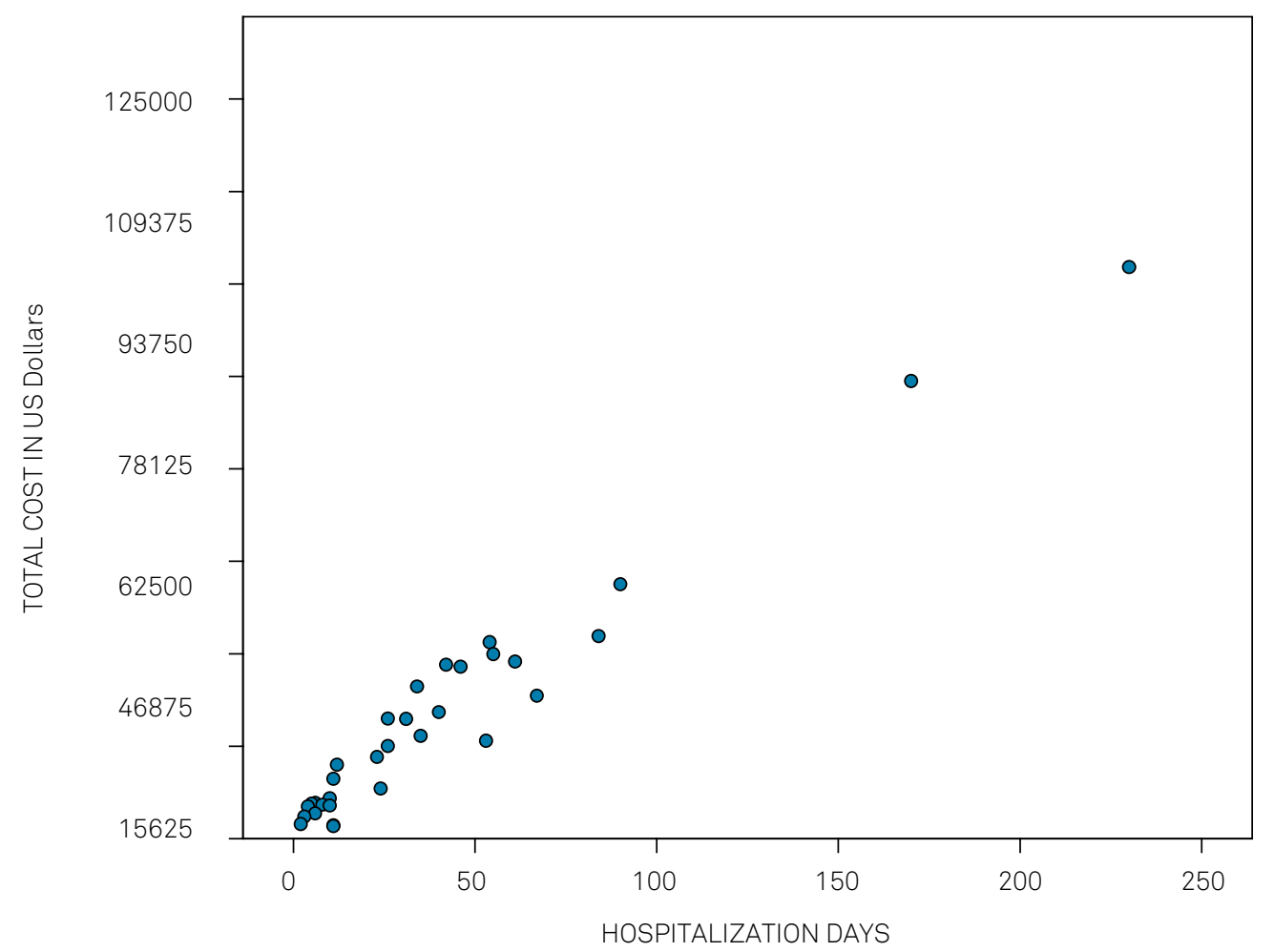

Figure 1. Positive and linear relation between days of hospitalization and cost (Spearman Correlation coefficient of 0.925)

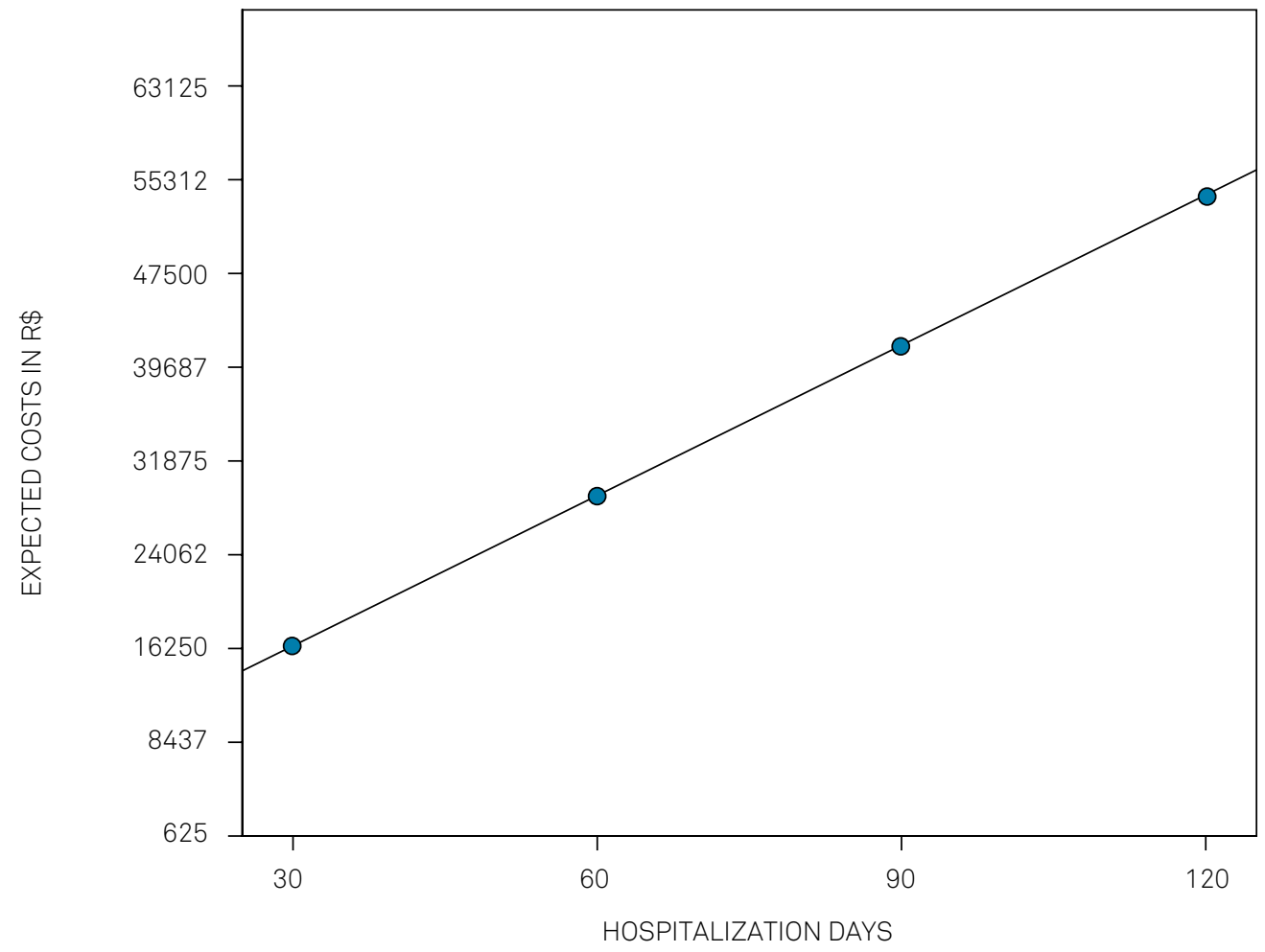

Figure 2. Linear model of the cost in Brazilian reals.

Considering outcomes and costs, the general mortality index was $68.7 \%$. Only 10 patients survived and among them five (15.6\% of the initial group of 32) had a good outcome (Glasgow Outcome Scale (GOS) score of 4 or 5). The total cost was R $\$ 2,116,960.22$ (US\$ 661,550.06) and the mean patient cost was $\mathrm{R} \$ 66,155.00$ (US\$20,673.44) (SD $\pm \mathrm{R} \$ 66,766.10$ (US\$ $22,255.37$ )), and the minimum value was R $\$ 6,883.84$ (US\$ 2,151.20) and the maximum of R\$ 309,119.80 (US\$ 96,599.94). 


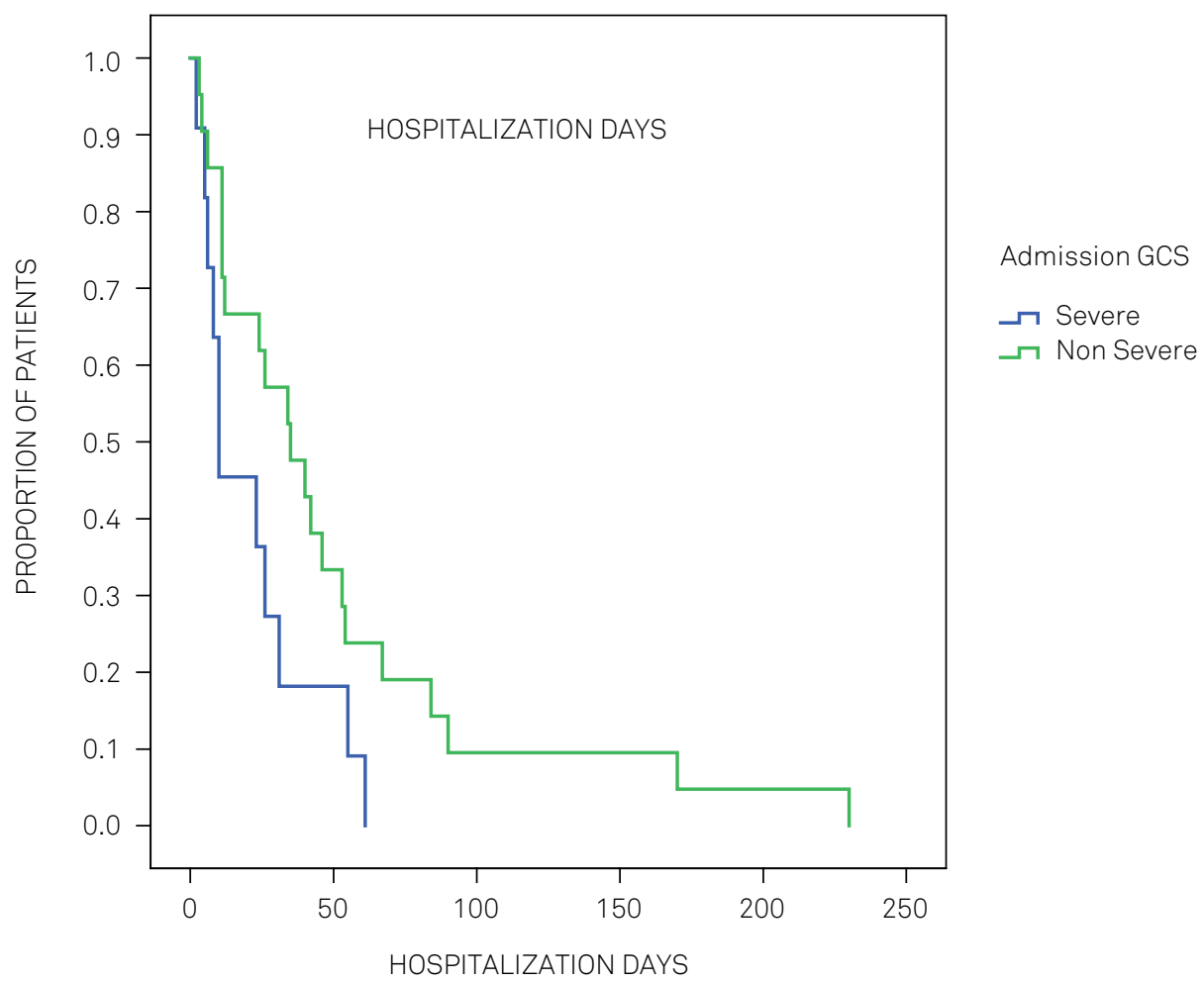

Figure 3. Proportion of patients for each hospitalization time according to TBI severity.

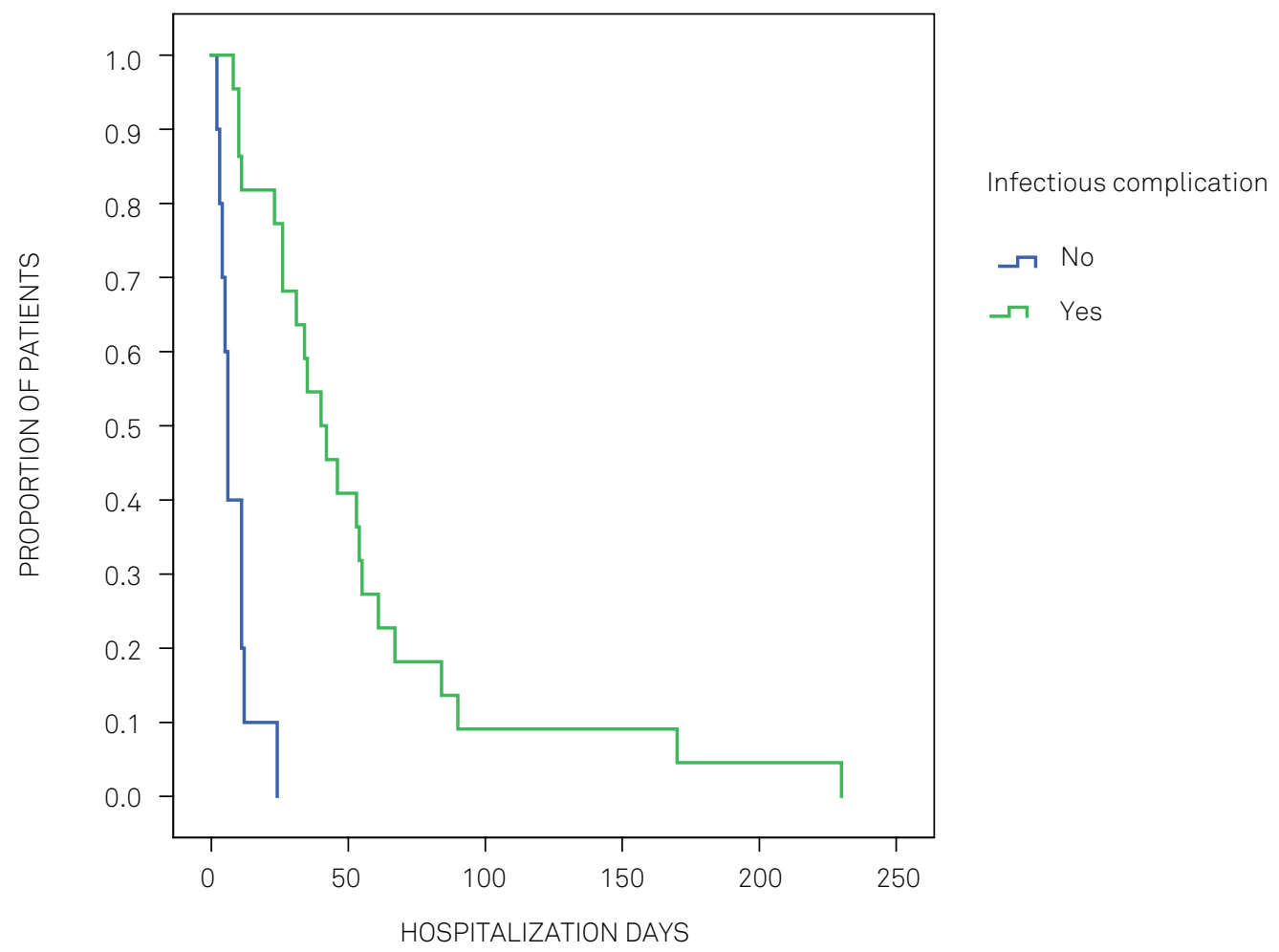

Figure 4. Proportion of patients for each hospitalization time according to the presence of infectious complications.

\section{DISCUSSION}

Decompressive craniectomy is a common neurosurgical procedure that aims to relieve raised intracranial pressure. Several situations could require this surgery for restoring encephalic hemodynamics ${ }^{1}$. TBI could require this procedure and, because of its global importance and socioeconomic impact, mainly in developing countries, 


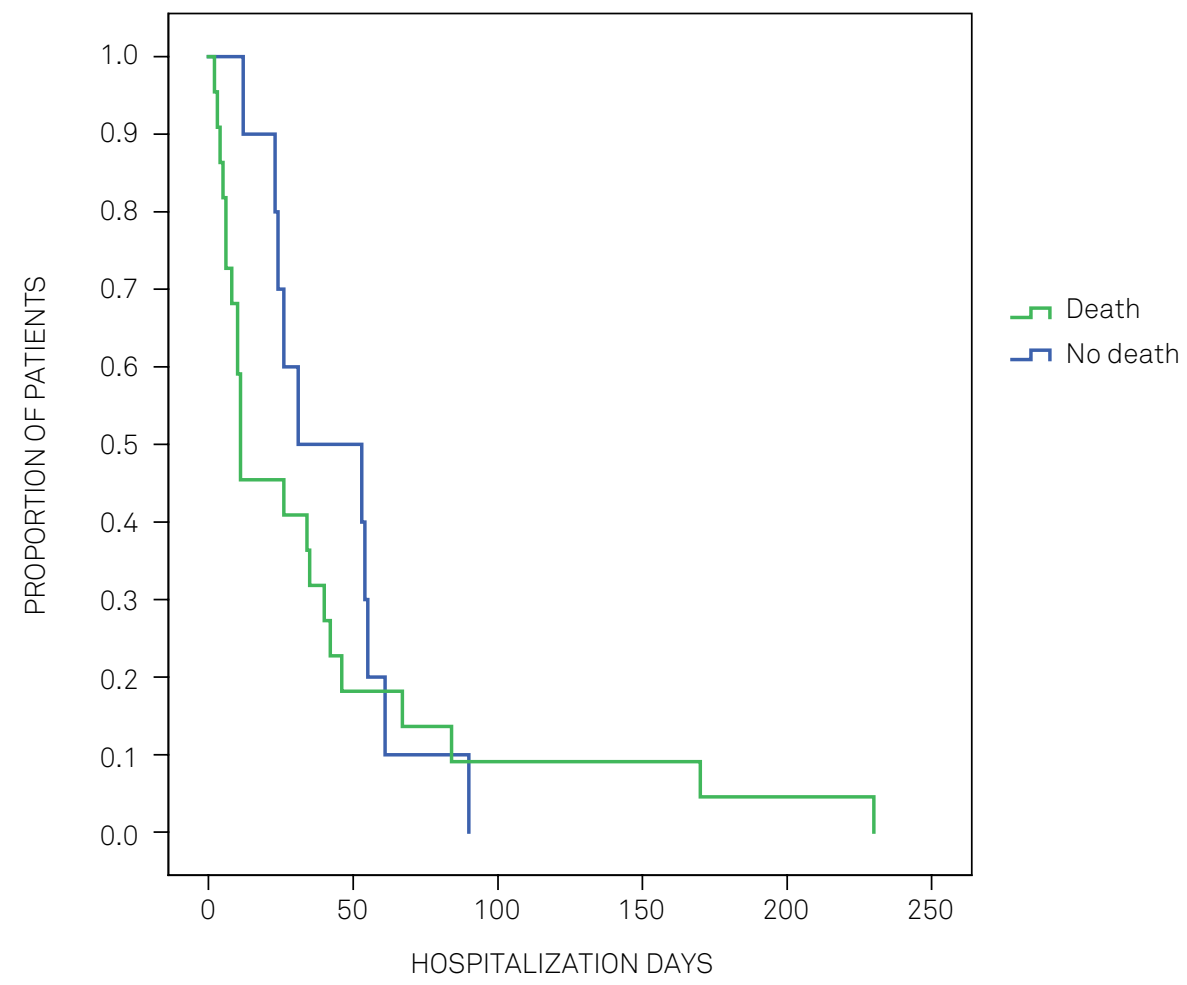

Figure 5. Proportion of patients for each hospitalization time according to outcome.

knowing the costs and outcomes makes a difference in the public health system.

Removal of the skullcap, as a type of therapeutic approach, has been used since $10,000 \mathrm{BC}^{10}$. Hippocrates initially described the types of brain trauma injuries that could be treated with burr holes ${ }^{11}$. However, only in 1901, did Theodor Kocher establish the theory that a skull opening could relieve raised intracranial pressure $^{12}$. Some years later, in 1908, Harvey Cushing described his own statistics of several patients with TBI treated with subtemporal decompressive craniectomy ${ }^{13}$. In the following decades, the use of decompressive craniectomy declined and few studies were undertaken to improve the technique ${ }^{12}$. However, in the 1990s, with the development of neurological intensive care and neuroimaging advances, a more extensive study of decompressive craniectomy returned and randomized analyses were performed to evaluate its effectiveness ${ }^{13}$. Therefore, from this moment on, guidelines describe decompressive craniectomy for strokes and TBI as an important and systematic therapeutic approach ${ }^{12}$.

In the treatment of raised intracranial pressure in TBI, decompressive craniectomy could be performed as a primary or secondary therapy. The former is performed during surgeries for hematomas (usually acute subdural hematoma) due to cerebral edema associated with transcalvarial herniation visualized intraoperatively, or for edema that may get worse in the postoperative period ${ }^{14,15,16}$. On the other hand, secondary therapies are those performed as a rescue measure, when all nonsurgical treatments for raised intracranial pressure control have not succeeded ${ }^{17,18}$.
In fact, the most common technique for unilateral decompressive craniectomy is a fronto-temporo-parietal incision with removal of the bone flap and dural opening (usually with a "starry" incision) $)^{19,20}$. This technique was used in the present study. Most of these patients were in poor general condition and, therefore, neurological intensive care is very important for improving prognosis and increased survival.

The technique and indications have already been discussed extensively in several articles ${ }^{13,20,21}$. Nevertheless, this study has a different focus and uncommon approach, namely, the cost of decompressive craniectomy, a procedure that represents the most severe and expensive treatment option for patients with TBI. The main indications for decompressive hemicraniectomy are edema after spontaneous subarachnoid hemorrhage, malignant middle cerebral artery infarct and post-traumatic edema related, or not, to adjacent focal lesions.

Several variables were determined and compared to the patient outcome (evaluated through the GOS). They included gender, age, type of brain lesion, associated pathologies, the operated hemisphere side, infectious complications and admission GCS. However, none of these had a significant correlation with the patient outcome. Another cost analysis study involving 54 patients also did not show an association between age and GCS admission with the patient's outcome $^{22}$, despite these variables typically being considered as prognostic factors ${ }^{21}$.

When the time until surgery was considered, there have been some divergent studies with conflicting data concerning outcomes. Therefore, despite this study not indicating a 
significant association between these variables, others have shown better outcomes with early surgery ${ }^{3,23}$ and some have also described a decrease in mortality ${ }^{22,24}$. In this context, it is valuable to note that our mortality rate was $68.7 \%$, a value greater than many other studies, in which the mortality index was $28-41 \%$ with aggressive treatment, and about $41-51 \%$ with nonsurgical treatments (such as hypothermia and hyperosmolar solutions) $)^{9,25}$. Our high mortality rate could be because this research was performed in a large center that receives patients from an extensive geographic area, many of whom arrive several hours after the injury, in a non-optimal time and, therefore, in a severe health status, contributing to increased mortality.

Thus, hospitalization days have a direct impact on TBI decompressive craniectomy patient costs and, therefore, an analysis was performed to describe which factors are correlated with days of hospitalization and have an influence over the final cost.

Infections could be correlated with greater costs because these patients require broad-spectrum antibiotics for longer periods and, as well, several procedures such as gastrostomy and tracheostomy may be performed in chronic patient care.

It has previously been described in some studies that an increase in antibiotic use in hospitalized patients, mainly broadspectrum, generally have higher $\operatorname{costs}^{26}$. In most cases, multidrug resistant bacteria were isolated. Therefore, these drugs have significant impact on costs during hospitalization ${ }^{27,28}$.

Comparing hospitalization days with the outcomes, it can be seen that survivors had a longer period of hospitalization (Figure 5). A large trial published in 2011, known as DECRA ${ }^{17}$, revealed that patients undergoing craniectomy had worse scores on the Extended GOS than those receiving standard care. As well, in a randomized study in 2016, Hutchinson et al. observed that decompressive craniectomy could reduce mortality; however, several of the survivors were in a vegetative state with a low functional status ${ }^{18}$.

This study has some limitations inherent in its model. Because it was a retrospective analysis, data was obtained through medical records and patients could not be followed up. Another limitation is the absence of a controlled group. However, in this context, conservative treatment for critical neurological patients is a difficult choice, considering that a neurosurgical procedure ${ }^{17}$ is a rescue measure and usually indicated when no other therapy has succeeded. A nonsurgical approach is seen as an ethical dilemma.

Only the direct costs of decompressive craniectomy were described. Rehabilitation, homecare support, social security and loss of productivity were considered as indirect costs and not evaluated in this study.

Patients who do survive generate greater hospitalization costs and the majority will require future hospitalizations for treatment of clinical complications and other procedures, such as ventricular shunts and cranioplasty. Some studies have demonstrated that the real cost of these patients is about 10-15 times greater than the cost of the treatment in acute phase ${ }^{29,30}$.

This was the first Latin-American study aimed at determining the direct cost of decompressive craniectomy in the public health system and the main factors related to the cost of this procedure. An epidemiological profile was also described, which helps to guide educational strategies for reduction and prevention of this socioeconomic impact.

New techniques have recently been studied to replace the decompressive craniectomy in TBI patients. Cherian et al. ${ }^{31}$ described a patient series in which he defends the use of microsurgical cisternostomy in TBI patients who had a classic indication for decompressive craniectomy, revealing a better outcome. This was a pioneer study and more research is required to validate this technique.

In conclusion, decompressive craniectomy is a procedure that aims to relieve raised intracranial pressure in seriously injured patients; however, it has a high mortality rate (68\%) and poor outcomes (15\%). Despite the high costs in developed countries, this was the first study that aimed to perform an analysis in developing countries. The mean cost per patient was about $\mathrm{R} \$ 66,000$ (US $\$ 20,625)$ during hospitalization, with infectious complications having a greater impact on the total cost.

The knowledge of the costs of decompressive craniectomy in developing countries in which TBIs are very common and have a huge socioeconomic impact is important to guide public health policies and resource allocation. Based on this study, results that determine the high costs associated with decompressive craniectomy for TBI, lead us to believe that prevention policies must be improved and other therapeutic modalities should be considered in this situation.

\section{References}

1. Kolias AG, Kirkpatrick PJ, Hutchinson PJ. Decompressive craniectomy: past, present and future. Nat Rev Neurol. 2013 Jul;9(7):405-15. https://doi.org/10.1038/nrneurol.2013.106

2. Hutchinson P, Timofeev I, Kirkpatrick P. Surgery for brain edema. Neurosurg Focus. 2007 May;22(5):E14. https://doi.org/10.3171/foc.2007.22.5.15

3. Marmarou A. A review of progress in understanding the pathophysiology and treatment of brain edema. Neurosurg Focus. 2007 May;22(5):E1. https://doi.org/10.3171/foc.2007.22.5.2
4. Unterberg AW, Stover J, Kress B,

Kiening KL. Edema and brain trauma.

Neuroscience. 2004;129(4):1021-9.

https://doi.org/10.1016/j.neuroscience.2004.06.046

5. Whitmore RG, Thawani JP, Grady MS, Levine JM,

Sanborn MR, Stein SC. Is aggressive treatment

of traumatic brain injury cost-effective?

J Neurosurg. 2012 May;116(5):1106-13.

https://doi.org/10.3171/2012.1.JNS11962 
6. Danish SF, Barone D, Lega BC, Stein SC. Quality of life after hemicraniectomy for traumatic brain injury in adults. A review of the literature. Neurosurg Focus. 2009 Jun;26(6):E2. https://doi.org/10.3171/2009.3.FOCUS945

7. Lemcke J, Ahmadi S, Meier U. Outcome of patients with severe head injury after decompressive craniectomy. Acta Neurochir Suppl (Wien). 2010;106:231-3. https://doi.org/10.1007/978-3-211-98811-4_43

8. Jorge MHPM, Koizumi MS. [Current direct costs of hospital admissions due to external causes: analysis in the State of São Paulo, 2000]. Rev Bras Epidemiol. 2004;7(2):228-38. Portuguese. https://doi.org/10.1590/S1415-790X2004000200012

9. Jennett B, Teasdale G, Galbraith S, Pickard J, Grant H, Braakman R et al. Severe head injuries in three countries.J Neurol Neurosurg Psychiatry. 1977 Mar;40(3):291-8. https://doi.org/10.1136/jnnp.40.3.291

10. Kshettry VR, Mindea SA, Batjer HH. The management of cranial injuries in antiquity and beyond. Neurosurg Focus. 2007;23(1):E8. https://doi.org/10.3171/FOC-07/07/E8

11. Panourias IG, Skiadas PK, Sakas DE, Marketos SG. Hippocrates: a pioneer in the treatment of head injuries. Neurosurgery. 2005 Jul;57(1):181-9. https://doi.org/10.1227/01.NEU.0000163416.66374.48

12. Münch E, Horn P, Schürer L, Piepgras A, Paul T, Schmiedek P. Management of severe traumatic brain injury by decompressive craniectomy. Neurosurgery. 2000 Aug;47(2):315-22. https://doi.org/10.1097/00006123-200008000-00009

13. Hutchinson PJ, Corteen E, Czosnyka M, Mendelow AD, Menon DK, Mitchell P et al. Decompressive craniectomy in traumatic brain injury: the randomized multicenter RESCUEicp study (www. RESCUEicp.com). Acta Neurochir Suppl (Wien). 2006;96:17-20. https://doi.org/10.1007/3-211-30714-1_4

14. Bullock MR, Chesnut R, Ghajar J, Gordon D, Hartl R, Newell DW et al. Surgical management of acute subdural hematomas. Neurosurgery. 2006 Mar;58(3 Suppl):S16-24. https://doi.org/10.1227/01.NEU.0000210364.29290.C9

15. Compagnone C, Murray GD, Teasdale GM, Maas AI, Esposito D, Princi $P$ et al. The management of patients with intradural post-traumatic mass lesions: a multicenter survey of current approaches to surgical management in 729 patients coordinated by the European Brain Injury Consortium. Neurosurgery. 2005 Dec;57(6):1183-92. https://doi.org/10.1227/01.NEU.0000186239.10915.09

16. Coplin WM, Cullen NK, Policherla PN, Vinas FC, Wilseck JM, Zafonte RD et al. Safety and feasibility of craniectomy with duraplasty as the initial surgical intervention for severe traumatic brain injury. J Trauma. 2001 Jun;50(6):1050-9. https://doi.org/10.1097/00005373-200106000-00013PMID:11426120

17. Cooper DJ, Rosenfeld JV, Murray L, Arabi YM, Davies AR, D'Urso P et al.; DECRA Trial Investigators; Australian and New Zealand Intensive Care Society Clinical Trials Group. Decompressive craniectomy in diffuse traumatic brain injury. N Engl J Med. 2011 Apr;364(16):1493-502. https://doi.org/10.1056/NEJMoa1102077

18. Hutchinson PJ, Kolias AG, Timofeev IS, Corteen EA, Czosnyka M, Timothy $\mathrm{J}$ et al.; RESCUEicp Trial Collaborators. Trial of Decompressive Craniectomy for Traumatic Intracranial Hypertension. N Engl J Med. 2016 Sep;375(12):1119-30. https://doi.org/10.1056/NEJMoa1605215
19. Park J, Kim E, Kim GJ, Hur YK, Guthikonda M. External decompressive craniectomy including resection of temporal muscle and fascia in malignant hemispheric infarction. J Neurosurg. 2009 Jan;110(1):101-5. https://doi.org/10.3171/2008.4.17540

20. Timofeev I, Santarius T, Kolias AG, Hutchinson PJ. Decompressive craniectomy: operative technique and perioperative care. Adv Tech Stand Neurosurg. 2012;38:115-36. https://doi.org/10.1007/978-3-7091-0676-1_6

21. Kakar V, Nagaria J, John Kirkpatrick P. The current status of decompressive craniectomy. Br J Neurosurg. 2009 Apr;23(2):147-57. https://doi.org/10.1080/02688690902756702

22. Malmivaara K, Kivisaari R, Hernesniemi J, Siironen J. Cost-effectiveness of decompressive craniectomy in traumatic brain injuries. Eur J Neurol. 2011 Apr;18(4):656-62. https://doi.org/10.1111/j.1468-1331.2010.03294.x

23. Polin RS, Shaffrey ME, Bogaev CA, Tisdale N, Germanson T, Bocchicchio B et al. Decompressive bifrontal craniectomy in the treatment of severe refractory posttraumatic cerebral edema. Neurosurgery. 1997 Jul;41(1):84-92. https://doi.org/10.1097/00006123-199707000-00018

24. Morgalla MH, Will BE, Roser F, Tatagiba M. Do long-term results justify decompressive craniectomy after severe traumatic brain injury? J Neurosurg. 2008 Oct;109(4):685-90. https://doi.org/10.3171/JNS/2008/109/10/0685

25. Stein SC, Georgoff P, Meghan S, Mizra K, Sonnad SS. 150 years of treating severe traumatic brain injury: a systematic review of progress in mortality. J Neurotrauma. $2010 \mathrm{Jul} ; 27(7): 1343-53$. https://doi.org/10.1089/neu.2009.1206

26. Pestotnik SL, Classen DC, Evans RS, Burke JP. Implementing antibiotic practice guidelines through computer-assisted decision support: clinical and financial outcomes. Ann Intern Med. 1996 May;124(10):884-90. https://doi.org/10.7326/0003-4819-124-10-199605150-00004

27. Mauldin PD, Salgado CD, Hansen IS, Durup DT, Bosso JA. Attributable hospital cost and length of stay associated with health care-associated infections caused by antibiotic-resistant gram-negative bacteria. Antimicrob Agents Chemother. 2010 Jan;54(1):109-15. https://doi.org/10.1128/AAC.01041-09

28. Ng E, Earnest A, Lye DC, Ling ML, Ding Y, Hsu LY. The excess financial burden of multidrug resistance in severe gram-negative infections in Singaporean hospitals. Ann Acad Med Singapore. 2012 May;41(5):189-93.

29. Murray CJL, Lopez AD. The global burden of disease: a comprehensive assessment of mortality and disability from diseases, injuries, and risk factors in 1990 and projected to 2020. Geneva:The Harvard School of Public Health; 1996.

30. Pickard JD, Bailey S, Sanderson H, Rees M, Garfield JS. Steps towards cost-benefit analysis of regional neurosurgical care. BMJ. 1990 Sep;301(6753):629-35. https://doi.org/10.1136/bmj.301.6753.629

31. Cherian I, Bernardo A, Grasso G. Cisternostomy for traumatic brain injury: pathophysiological mechanisms and surgical technical notes. World Neurosurg. 2016 May;89:51-7. https://doi.org/10.1016/j.wneu.2016.01.072 